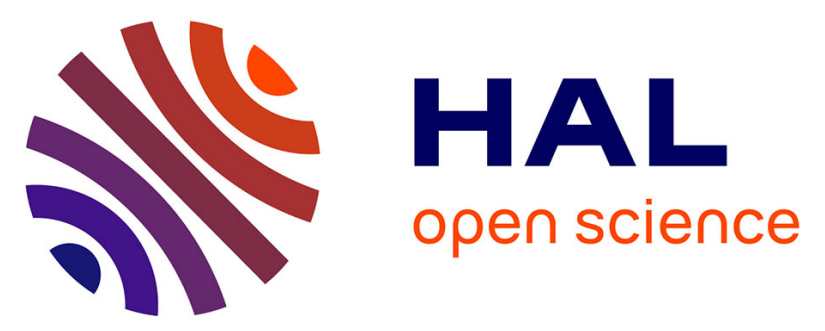

\title{
Studies of the dynamic expression of the Xenorhabdus FliAZ regulon reveal atypical iron-dependent regulation of the flagellin and haemolysin genes during insect infection.
}

Grégory Jubelin, Sylvie Pages, Anne Lanois, Marie-Hélène Boyer, Sophie S. Gaudriault, Jean-Baptiste Ferdy, Alain Givaudan

\section{To cite this version:}

Grégory Jubelin, Sylvie Pages, Anne Lanois, Marie-Hélène Boyer, Sophie S. Gaudriault, et al.. Studies of the dynamic expression of the Xenorhabdus FliAZ regulon reveal atypical iron-dependent regulation of the flagellin and haemolysin genes during insect infection.. Environmental Microbiology, 2011, 13

(5), pp.1271-1284. 10.1111/j.1462-2920.2011.02427.x . hal-02644381

\author{
HAL Id: hal-02644381 \\ https://hal.inrae.fr/hal-02644381
}

Submitted on 28 May 2020

HAL is a multi-disciplinary open access archive for the deposit and dissemination of scientific research documents, whether they are published or not. The documents may come from teaching and research institutions in France or abroad, or from public or private research centers.
L'archive ouverte pluridisciplinaire HAL, est destinée au dépôt et à la diffusion de documents scientifiques de niveau recherche, publiés ou non, émanant des établissements d'enseignement et de recherche français ou étrangers, des laboratoires publics ou privés. 


\section{Studies of the dynamic expression of the Xenorhabdus FliAZ regulon reveal atypical iron-dependent regulation of the flagellin and haemolysin genes during insect infection}

\author{
Grégory Jubelin, ${ }^{1,2}$ Sylvie Pagès, ${ }^{1,2}$ Anne Lanois, ${ }^{1,2}$ \\ Marie-Hélène Boyer, ${ }^{1,2}$ Sophie Gaudriault, ${ }^{1,2}$ \\ Jean-Baptiste Ferdy ${ }^{3,4}$ and Alain Givaudan ${ }^{1,2 *}$ \\ ${ }^{1}$ INRA and ${ }^{2}$ Université Montpellier 2, UMR 1133 \\ Laboratoire EMIP, F-34000 Montpellier, France. \\ ${ }^{3}$ CNRS and ${ }^{4}$ Université Toulouse 3, UMR 5174 \\ Laboratoire EDB, F-31000, Toulouse, France.
}

\section{Summary}

Xenorhabdus nematophila engages in complex interactions with invertebrates, through its symbiosis with soil nematodes and its pathogenicity to a broad range of insect larvae. Among the regulatory proteins of Xenorhabdus involved in host interactions, the sigma factor FliA and the regulator FliZ, expressed from the fliAZ operon, play a key role in mediating the production of exoenzymes, motility and full virulence in insects (Lanois et al., 2008). In this study, we investigated the dynamics of the FliAdependent flagellin gene fliC and FliZ-dependent haemolysin genes $x a x A B$ during insect infection and nematode association by carrying out real-time expression analysis using an unstable GFP monitoring system. We showed that expression of the FliAZdependent genes in infected insects is not restricted to a specific tissue but increases significantly just prior to host death and reaches a maximal level in larvae cadaver. Using an iron availability reporter construct, we also showed that iron starvation conditions inhibit expression of FliAZ-dependent genes in vitro, as well as during the first steps of the infectious process. These findings shed further light on the role of the FliAZ regulon in the Xenorhabdus life cycle and suggest that iron may constitute a signal governing Xenorhabdus adaptation to shifting host environments.

Received 24 February, 2010; accepted 5 January, 2011. *For correspondence. E-mail givaudan@ univ-montp2.fr; Tel. (+33) 4671448 12; Fax (+33) 467144679.

\section{Introduction}

Xenorhabdus nematophila is a motile Gram-negative bacterium that infects and kills a wide range of insect larvae, including agriculturally relevant species such as the tobacco hornworm, Manduca sexta, and the cotton worm, Spodoptera littoralis (Forst and Tabatabai, 1997; Sicard et al., 2004). These enterobacteria also form a speciesspecific mutualistic association with the entomopathogenic nematode Steinernema carpocapsae (Thomas and Poinar, 1979; Cowles and Goodrich-Blair, 2008). The life cycle of $S$. carpocapsae nematodes includes reproductive stages occurring exclusively within host insect larvae. The nematode life cycle also includes a developmentally arrested stage termed infective juvenile (IJ). Xenorhabdus nematophila colonizes a discrete intestinal location in the IJ, known as the vesicle (Martens et al., 2003). In nature, IJs penetrate insects and release their bacterial symbionts into the host body cavity. The bacteria initially escape insect defence mechanisms by modulating the immune system (Ji and Kim, 2004; Park et al., 2007). They then colonize the haemolymph (the insect equivalent of blood) and connective tissues surrounding the anterior midgut, and finally invade the entire body of the larva, leading to its death (Sicard et al., 2004). Bacteria contribute to the mutualistic relationship by establishing and maintaining suitable conditions for nematode reproduction in the insect cadaver (Sicard et al., 2003). Xenorhabdus nematophila is also able to kill insects and grow within insect bodies independently of its nematode partner if introduced into the haemolymph by direct injection in the laboratory (Poinar and Thomas, 1966; Sicard et al., 2004).

Xenorhabdus nematophila produces a plethora of putative virulence factors, including toxins, lipases, haemolysins and proteases, which may contribute to pathogenicity and the modification of insect immunity (Forst et al., 1997; Herbert and Goodrich-Blair, 2007). In many cases, the inactivation of an individual factor has no effect on overall $X$. nematophila virulence. Several studies in the last 10 years have revealed the existence of a central regulatory network controlling $X$. nematophila pathogenesis (Goodrich-Blair and Clarke, 2007). The 
master regulator for flagellar synthesis and motility, FIhDC, has been shown to be required for full virulence in insects and for haemolysin and lipase production (Givaudan and Lanois, 2000). FlhDC synthesis is regulated by at least three other transcription factors having therefore pleiotropic effects and affecting virulence in insects (Park and Forst, 2006; Cowles et al., 2007; Richards et al., 2008). Transcriptional and phenotypic studies of the flagellar cascade clarified the respective roles of motility and other FlhDC-dependent factors in $X$. nematophila virulence (Park and Forst, 2006; Lanois et al., 2008). As in Escherichia coli (Liu and Matsumura, 1994), the flagellar class I operon product FlhDC is required for the transcription of class II genes encoding structural components of the flagellar hook-basal body in $X$. nematophila. FlhDC also controls expression of the alternative sigma factor FliA $\left(\sigma^{28}\right)$, which is required for the expression of class III products, including the flagellin monomer FliC (Givaudan and Lanois, 2000). In X. nematophila, the FIhD-dependent fliAZ operon has been identified as the key locus mediating the expression of genes involved in lipase, protease and haemolysin activities, motility and full virulence in insects (Park and Forst, 2006; Lanois et al., 2008). We demonstrated that FliZ controls the haemolysin genes $x a x A B$ and $x h I B A$ and full virulence in insects (Lanois et al., 2008). The two operons directly affected by FliZ encode haemolysins from two families. $\mathrm{XaxAB}$ is the prototype of a new extensive family of haemolysins with apoptotic and pore-forming activities in mammalian and invertebrate cells (Vigneux et al., 2007). The second FliZ-dependent haemolysin, XhIA, is a cell surface-associated haemolysin from a family characterized by a two-partner secretion system (Cowles and Goodrich-Blair, 2005). Haemolysins XhIA and XaxAB lyse erythrocytes and the two most common types of insect immune cell (granulocytes and plasmatocytes) (Brillard et al., 2001; Cowles and Goodrich-Blair, 2005).

To increase our understanding of the role of the FliAZ regulon in the life cycle of $X$. nematophila, investigations of the successive steps of the infectious process and the nematode symbiotic stage are required to determine the timing and sites of regulon expression. In addition, the timely deployment of bacterial determinants requires that Xenorhabdus are able to sense when they have gained entry into the insect haemocoel or into the IJ-stage nematode. Iron is a scarce soluble element in eukaryotic hosts and its low availability often constitute a signal indicating that pathogens have entered inside the host (Litwin and Calderwood, 1993). In this study, we showed that expression of the FliA-dependent gene fliC and the FliZdependent genes хах $A B$ are downregulated under iron starvation conditions in bacterial cultures as well as during the infectious process in living insects. In addition, a high expression level of the FliAZ-dependent genes in insect cadavers is correlated with the increase of iron availability in insect cadavers. These findings highlight the role of iron in regulating the expression of the FliAZ regulon during the insect infection phase of the Xenorhabdus life cycle.

\section{Results}

Temporal pattern of expression of the flagellin and FliZ-dependent haemolysin genes in bacterial cultures

Before characterizing the dynamics of the $X$. nematophila FliAZ regulon in invertebrate hosts, we first investigated the expression patterns of FliA- or FliZ-dependent genes in bacteria cultured in vitro. The FliA-dependent gene fliC, encoding the flagellin monomer, and the FliZ-dependent genes $x a x A B$ and $x h / B A$, both encoding haemolysins, were used as representative members of the FliAZ regulon. Promoter sequences of these genes were inserted into pPROBE-gfp[AAV], a highly stable vector (Miller et al., 2000) to create transcriptional fusions with the reporter gene $g f p[A A V]$, which encodes an unstable GFP (Andersen et al., 1998). Constructs were then introduced into the wild-type $X$. nematophila strain $\mathrm{F} 1$ and the patterns of expression of FliAZ-dependent genes were examined during growth in vitro. Fluorescence due to the expression of the $\mathrm{P}_{\text {flic }}-g f p[\mathrm{AAV}]$ fusion was first detected in the mid-exponential growth phase and peaked early in the stationary phase, subsequently decreasing in the late stationary phase (i.e. after $20 \mathrm{~h}$ of growth culture) (Fig. 1A). The temporal pattern of fliC expression is consistent with the bacterial motility observed during the growth of $X$. nematophila in LB medium (data not shown) (Forst and Boylan, 2002). In contrast expression of the haemolysin genes, $x a x A B$ and $x h I B A$ was not detected before the bacteria reached the stationary phase (Fig. 1A). For confirmation of the pattern of xax $A B$ expression, we monitored $x a x A$ mRNA synthesis by quantitative RT-PCR (qRT-PCR) and Xax activity for which we have a clear associated phenotype. The number of $x a x A$ transcripts increased rapidly during the early stationary phase as reported for the gfp[AAV] reporter gene (Fig. 1A), and then gradually decreased during late stationary phase (Fig. 1B). The detection of a third of the GFP signal in the medium of a 40-day-old culture of $X$. nematophila (data not shown) may account for the difference between the two quantification methods, as extracellular GFP is not degraded by specific bacterial proteases. Indeed, after centrifugation, the monitoring of bacterial cell fluorescence displayed a decrease of xax expression from $40 \mathrm{~h}$ (data not shown) to a lesser extent than in Fig. 1B. Expression of the xaxAB operon is also correlated, for both induction and extinction, with Xax cytolytic activity, which is detected during the early stationary phase (Fig. 1B) (Brillard et al., 2001). 

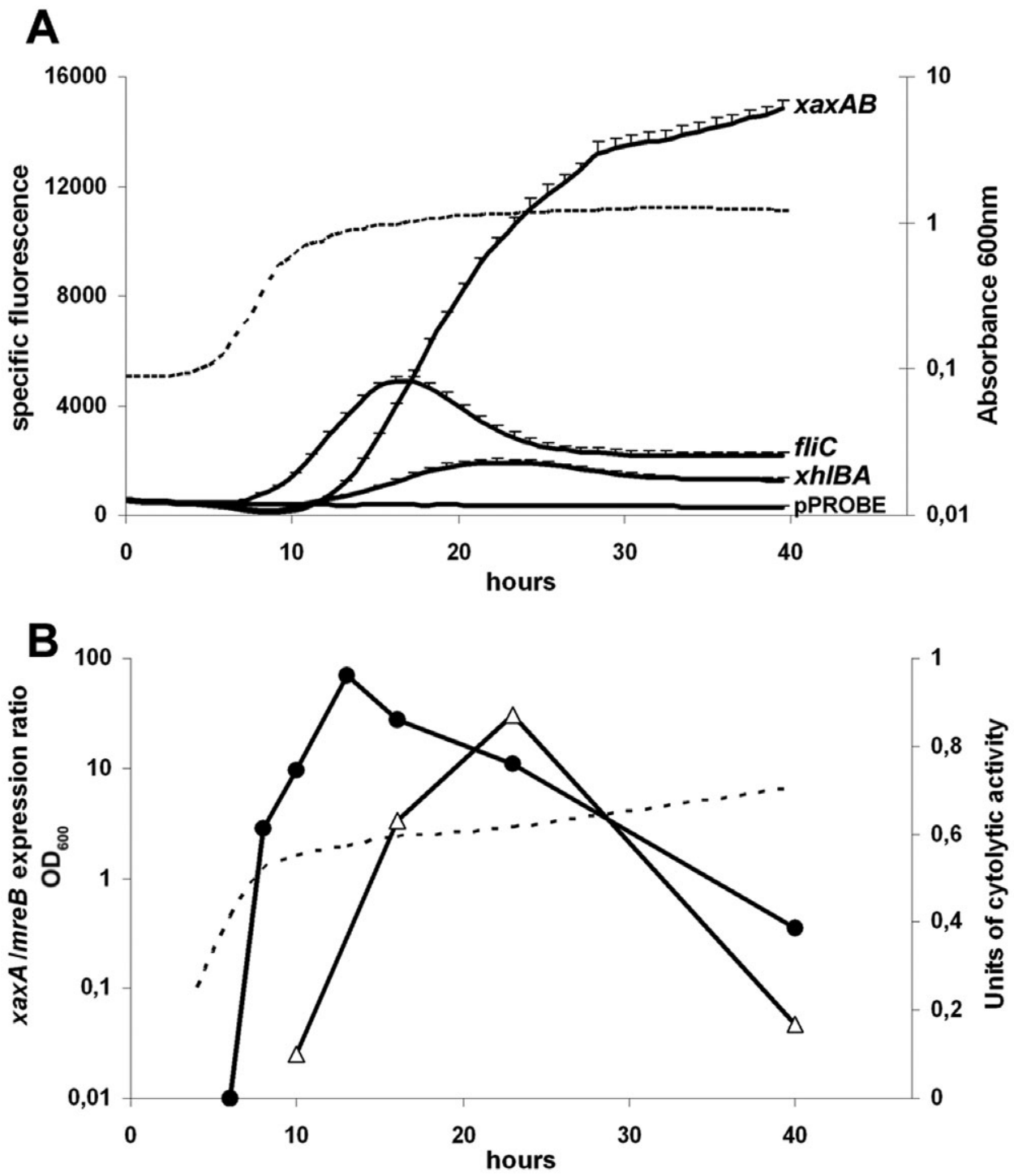

Fig. 1. Expression of the fliC, $x a x A B$ and $x h I B A$ genes during the growth in vitro of $X$. nematophila.

A. F1 strains carrying the $\mathrm{P}_{\text {ffic }}-g f p[\mathrm{AAV}], \mathrm{P}_{x a x A B}-g f p[\mathrm{AAV}]$ or $\mathrm{P}_{x h l B A}-g f p[\mathrm{AAV}]$ construct or the promoterless vector pPROBE-gfp[AAV] were grown in 96-well plates for $40 \mathrm{~h}$ and GFP fluorescence and absorbance at $600 \mathrm{~nm}$ were recorded every $30 \mathrm{~min}$. A representative growth curve is indicated by the dashed line. Specific fluorescence is the ratio between GFP fluorescence and absorbance at $600 \mathrm{~nm}$. The results are the means and standard errors of three independent assays.

B. Relationship between the amount of $x a x A$ transcript $(\bullet)$ and the cytolytic activity of the Xax toxin $(\Delta)$. Xenorhabdus nematophila F1 was grown in LB and $x a x A$ transcript levels were quantified by qRT-PCR. Data are presented as a ratio, with mreB used as the control mRNA. Xax activity is expressed in cytolytic units, as described elsewhere (Brillard et al., 2001). The growth curve is indicated by the dashed line.

Iron availability modulates the expression of flagellin and Fliz-dependent haemolysin genes in vitro

Extensive studies of flagellar gene expression in bacteria have shown that flagellum biosynthesis is affected by many environmental factors (for a review, see Soutourina and Bertin, 2003). For the identification of putative stimuli of flagellar and haemolysin gene expression in Xenorhabdus, $\mathrm{F} 1$ strains carrying the $\mathrm{P}_{\text {flic }}-g f f[\mathrm{AAV}]$ or $\mathrm{P}_{\text {xaxAB}}-g f p[\mathrm{AAV}]$ fusion constructs were grown in LB supplemented with various chemicals, and gene expres- sion was monitored by recording GFP fluorescence. Several of the compounds tested had no significant effect on the expression of fliC and xaxAB (Fig. 2). A second class of products [acetylphosphate (ACP) and acetate] enhanced fliC expression without modifying $x a x A B$ transcription. A third class of products significantly modulated expression of the $\mathrm{P}_{x a x A B}-g f p[\mathrm{AAV}]$ and

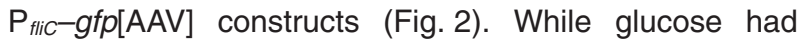
a positive effect on fliC expression and, to a lesser extent on хах $A B$ expression, p-nitrophenylglycerine (PNPG), a repressor of swarming motility, ethylene- 


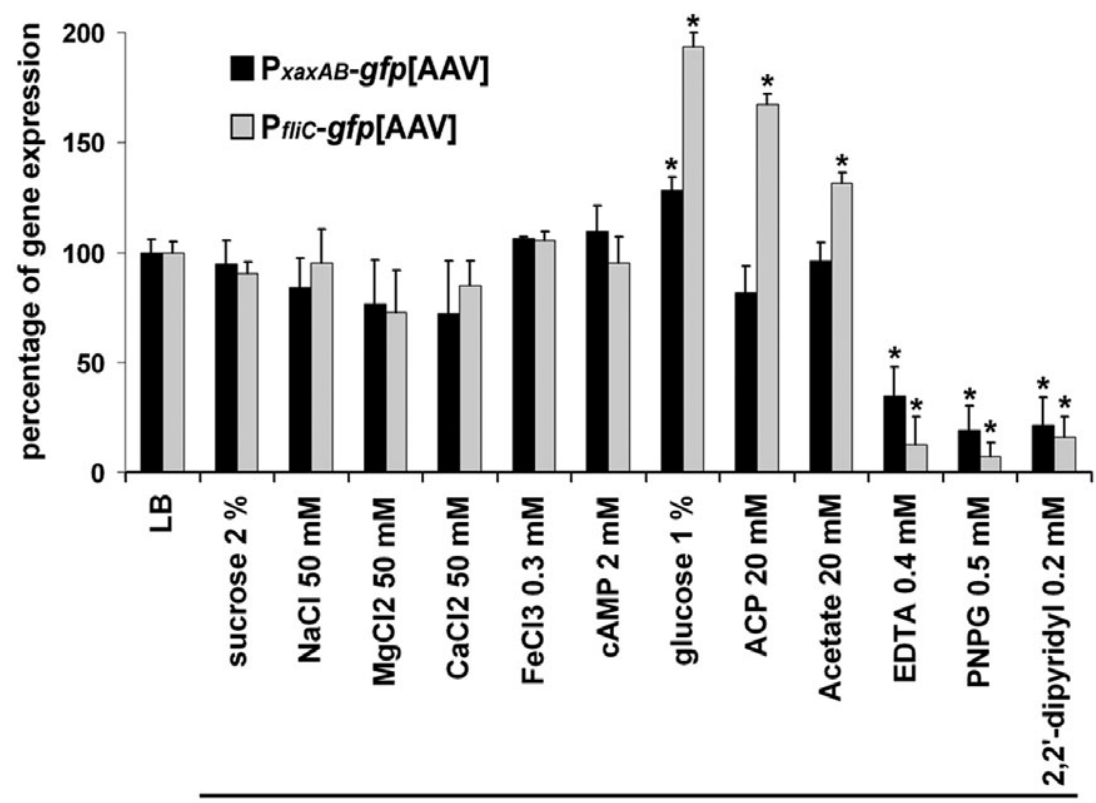

Fig. 2. Effects of various chemical compounds on the expression of $\mathrm{fliC}$ and $x a x A B$ in vitro. $\mathrm{F} 1$ strains carrying the $\mathrm{P}_{\text {fic }}-g f p[\mathrm{AAV}]$ or $\mathrm{P}_{x a x A B}-g f p[\mathrm{AAV}]$ construct were grown as shown in Fig. 1A, except that the LB was supplemented with the various products indicated. Maximal gene expression levels during growth in LB were taken as the standard expression levels (equivalent to $100 \%$ ). For other growth conditions, results are indicated as a percentage of gene expression in LB. None of the tested conditions affected the growth rate of $X$. nematophila (data not shown). The results shown are the means and standard errors from three to five independent assays. Significant differences with the standard LB growth condition $(P$-value $<0.01$, Wilcoxon rank sum test) are indicated with asterisks $\left({ }^{*}\right)$.

\section{LB +}

diamine-tetraacetic acid (EDTA), a divalent cation chelator, and 2,2'-dipyridyl, a chelator more specifically targeting iron, significantly reduced expression of both $g f p$ fusions (Fig. 2).

As iron is essential for the successful establishment of most pathogens in their hosts, we focused on irondependent modulation of the flagellar regulon. We constructed a reporter fusion to monitor iron bioavailability during $X$. nematophila growth. The gfp[AAV] gene was placed under the control of the promoter sequence from the XNC1-1298 gene, which is the first gene of a locus putatively encoding an iron-chelating siderophore. Based on homology between the protein predicted from XNC11298 and the siderophore RhbF (Martinez et al., 1994; Lynch et al., 2001), the XNC1-1298 gene was renamed $x h b F$. As expected, expression of the $\mathrm{P}_{x h b F}-g f p[\mathrm{AAV}]$ reporter construct was clearly detected when 2,2'dipyridyl was added to the culture medium (Fig. 3). In contrast, very weak expression was recorded in LB, in LB supplemented with the non-metal-chelating agent 4,4'-dipyridyl (used as a negative control) or when $\mathrm{FeSO}_{4}$ was added in excess to the medium containing 2,2'-dipyridyl. These data indicate that the $\mathrm{P}_{x h b F}$ $g f p[\mathrm{AAV}]$ reporter fusion construct is an effective tool for detecting iron depletion. Whereas 4,4'-dipyridyl had no effect on the expression of fliC and xaxAB, 2,2'-dipyridyl significantly decreased the expression of these genes by factors of 3.9 and 2.8 respectively (Fig. 3). The expression levels of fliC and $x a x A B$ were restored by adding excess $\mathrm{FeSO}_{4}$ to LB containing 2,2'-dipyridyl, demonstrating that iron deprivation was responsible for the repression of the flic and $x a x A B$ genes. The iron dependence of $x h I B A$ regulation was less apparent, as fluorescence levels in the presence of 2,2'-dipyridyl were lower than those in LB alone by a factor of only 1.4 $(P$-value $>0.01)$. Iron-dependent modulation of FliAZdependent gene expression was confirmed by qRTPCR. Indeed, levels of the flic, xaxA and $x h / A$ transcripts were significantly decreased by factors of 11 , 11 and 5 , respectively, following the addition of 2,2'dipyridyl to the growth medium (Fig. S1). qRT-PCR experiments also confirmed that the expression of $x h b F$ gene was regulated by iron (Fig. S1). Altogether, these results demonstrate that expression of the FliAZdependent genes in Xenorhabdus requires the presence of iron.

In addition, we investigated the possible direct involvement of Fur, the major regulatory protein modulating iron-dependent gene expression in bacteria (Escolar et al., 1999) in the iron-dependent expression of FlhDdependent genes in $X$. nematophila. By carrying out chromatin immunoprecipitation (ChIP) assays with an HA-tagged Fur protein we showed that Fur belongs to the transcriptional complex binding to the promoter region of $x h b F$. Indeed, the HA-immunoprecipitated DNA fraction was significantly enriched with $x h b F$ promoter region DNA, particularly in presence of iron in growth media (Fig. S2) (compare with the non-target mreB promoter sequence). In contrast, ChIP experiments revealed no specific enrichment in fliC, xaxA, xh/B, fliA and $f / h D$ promoter sequences, whatever the growth conditions, showing that Fur does not directly participate to the transcriptional activation of flagellar gene promoters. 

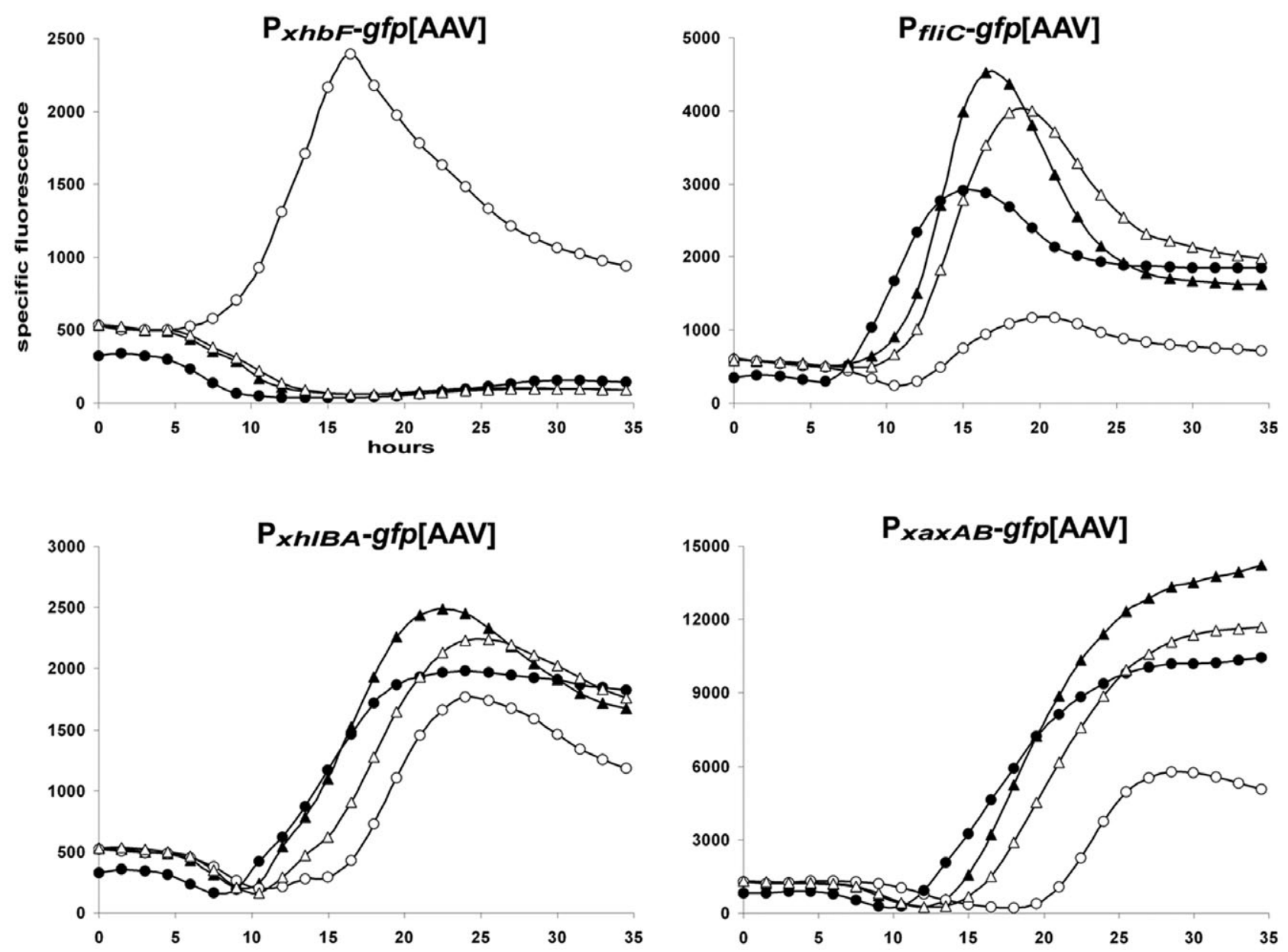

Fig. 3. Iron depletion inhibits the expression of FliAZ-dependent genes. F1 strains carrying the $\mathrm{P}_{f i i c}-g f p[\mathrm{AAV}], \mathrm{P}_{x a x A B}-g f p[\mathrm{AAV}], \mathrm{P}_{x h l B A}-g f p[\mathrm{AAV}]$ or positive control $\mathrm{P}_{x h b F}-g f p[\mathrm{AAV}]$ construct were grown as shown in Fig. 1A, except that LB ( $\left.\mathbf{\Delta}\right)$ was supplemented with $0.15 \mathrm{mM} 4,4^{\prime}$-dipyridyl

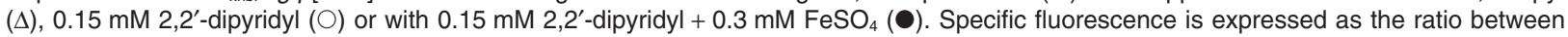
GFP fluorescence and absorbance at $600 \mathrm{~nm}$. The results are representative of five independent assays. Comparison of gene expression level between growth conditions was realized at the time point of maximal expression in LB $+2,2^{\prime}$-dipyridyl using the statistical model described in Experimental procedures and correcting for differences in microplate reader settings between independent experiments. Significant differences $(P$-value $<0.01)$ with the standard LB growth condition were detected for $x h b F$, fliC, xaxAB in presence of $2,2^{\prime}$-dipyridyl and for $x h b F$ in presence of 2,2'-dipyridyl $+\mathrm{FeSO}_{4}$. No significant difference was detected in presence of 4,4'-dipyridyl.

Qualitative analysis of fliC and xaxAB gene expression during the insect infectious process

In a first attempt, we carried out experiments to compare the behaviour of $F 1$ strains in insect with and without the various gfp[AAV] constructs. As previously shown with other GFP-labelled $X$. nematophila strains (Sicard et al., 2004), tagging $X$. nematophila with a gfp[AAV] construct, regardless of the precise nature of that construct, had no effect on Xenorhabdus growth kinetics in infected larvae or the $L T_{50}$ value, which was estimated at $28 \mathrm{~h}$ post infection (data not shown). We then investigated the infectious process in detail, by delineating four different stages in the infectious process (Fig. 4A): (i) the early septicaemic stage (ES), when the bacteria grow without killing the insect, (ii) the lethal septicaemic stage (LS), when septicaemia $\left(\sim 10^{8}\right.$ bacteria per insect larva) leads to insect death, (iii) the early cadaveric stage (EC), when about $90 \%$ of the larvae are dead, and (iv) the late cadaveric stage (LC), 1 day after insect death.

First, we observed the fluorescence of whole larvae infected with $X$. nematophila carrying the various $g f p[A A V]$ constructs with macro/zoom optics. While the bioimaging of larvae did not allow detection of fluorescence in whole animal before the LS stage, the fluorescence emitted by late LS stage larvae was evenly distributed throughout the insect body, for all gfp[AAV] constructs (Fig. 4B). We previously showed that the first sites within the insect haemocoel to be colonized by $X$. nematophila are the haemolymph and the connective tissues surrounding the 
A

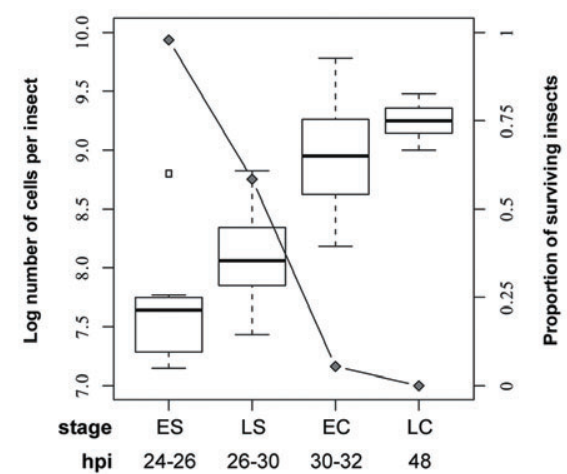

B
larvae
$\begin{gathered}\text { connective } \\ \text { tissue }\end{gathered}$

stage

D31 LS

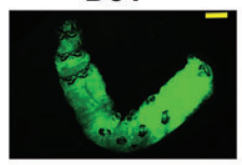

LS

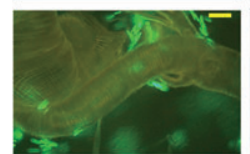

ES
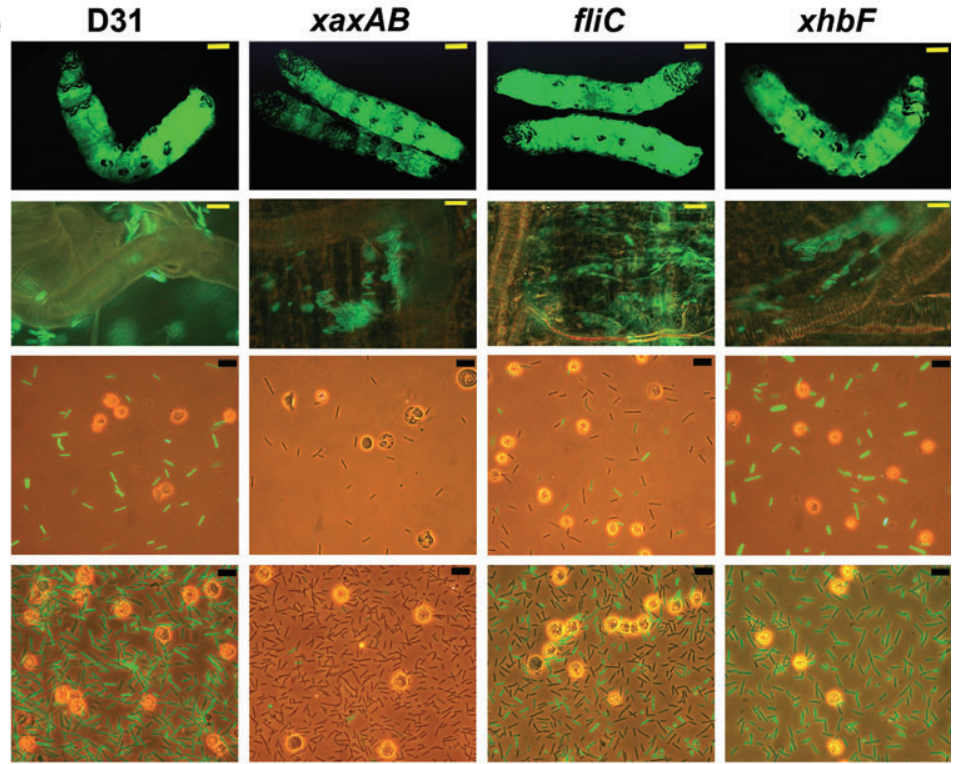

LS
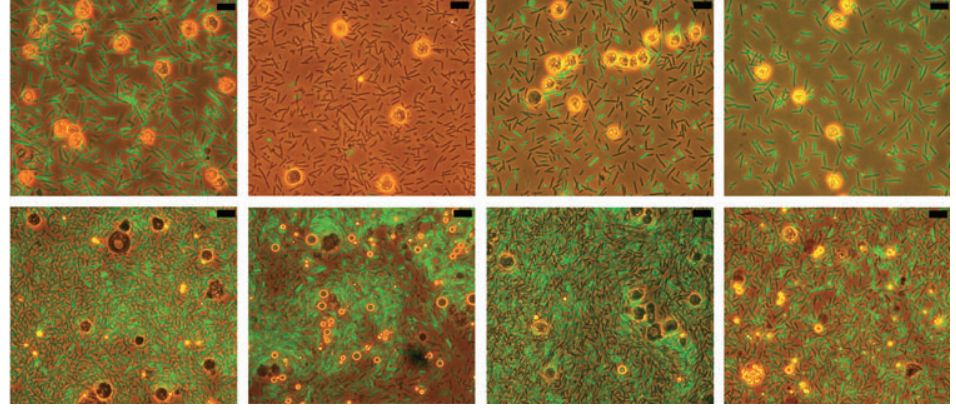

Fig. 4. Temporal and spatial expression of the flagellin and haemolysin genes during different stages of insect infection. For each experiment, at time zero, we injected $10^{4}$ bacteria into the haemocoel of the insect larvae.

A. Log-transformed numbers of bacterial cells are indicated for each of the four infection stages (see the text for explanation of the infection stages). For each stage, the horizontal thick line indicates the median number of cells, and the box corresponds to the range within which $75 \%$ of the observations fall. The error bars correspond to the range of observed values once potential outliers (open squares) are excluded. Potential outliers are defined as values that deviating by more than 1.5 times the box height from the box limit. Diamonds indicate the proportion of surviving insects for each of the four stages. hpi, hours post infection.

B. In the upper panel, whole larvae from late LS stage were observed with a fluorescence macroscope, with an exposure time set to 600 ms for photography (bars, $2.5 \mathrm{~mm}$ ). The LS stage larvae were also dissected and connective tissues were observed by fluorescence microscopy (bars, $5 \mu \mathrm{m}$ ). Other panels below depict haemolymph samples from ES, LS and EC stage larvae infected with F1 strains carrying the indicated gfp constructs observed by fluorescence microscopy. Pictures were taken using both phase-contrast and GFP fluorescence illumination (bars, $5 \mu \mathrm{m})$.

anterior midgut (Sicard et al., 2004). Epifluorescence microscopy analysis of these two tissues during LS stage revealed that there was no difference in spatial expression pattern between FliAZ-dependent genes and a constitutive reporter, D31 (Fig. 4B). Thus, the expression of flagellar genes is not tissue-specific during insect infection.

We next analysed haemolymph samples of infected larvae at each stage to determine the temporal expression of each gfp construct. We observed that bacteria 
carrying the $\mathrm{P}_{x a x A B}-g f p[\mathrm{AAV}]$ construct were not fluorescent at the ES stage (and only few bacterial cells were fluorescent for $\mathrm{fliC}$ ) whereas bacteria harbouring the D31 or $x h b F$ reporter constructs were (Fig. 4B). Fluorescence from bacteria carrying the $\mathrm{P}_{\text {flic }}-g f p[\mathrm{AAV}]$ and $\mathrm{P}_{x a x A B}-g f p[\mathrm{AAV}]$ constructs started to be clearly detected in haemolymph samples during the LS and EC stages, respectively, indicating that flagellin and haemolysin genes were indeed expressed in insect cadavers. Late expression of flagellar genes during the infectious process is in agreement with observation of motile cells and measurement of haemolytic activities in LC stage larvae (data not shown). It is noteworthy that fliC and хах $A B$ gene expression is heterogeneous at the cellular level in contrast to bacteria carrying the other gfp constructs (Fig. 4B). Altogether, these findings indicate that flagellin and haemolysin gene expression is mostly detected concomitantly to larvae death.

\section{Late expression of the fliC and xaxAB genes is} correlated with iron availability in infected insects

Since iron modulates expression level of FliAZ-dependent genes in vitro, we used a quantitative assay of GFP fluorescence to investigate possible interactions between fliC and $x а x A B$ gene expression and iron availability during insect infection. Control experiments were first carried out to determine whether the fluorescence emitted from the constitutive D31 construct was correlated with bacterial counts in the body of the insect in larvae treated or not with an exogenous source of iron. Infected larvae at various stages of infection were individually crushed and fluorescence and bacterial counts were determined for each insect lysate. The fluorescence of the $\mathrm{P}_{\mathrm{D} 31}-g f p[\mathrm{AAV}]$ fusion construct was statistically predicted as a linear function of the number of bacteria for all infectious stages (Durbin-Watson test on residuals, DW $=1.672$, $P$-value $=0.1620$; see also Fig. 5A). Similar results were obtained in larvae treated with an exogenous source of iron, indicating that iron did not affect expression of $\mathrm{P}_{\mathrm{D} 31}-$ gfp[AAV] construct (GLM with gamma-distributed error, $F_{1,98}=0.655, P=0.4203$ for the overall effect of iron, $F_{2,96}=0.677, P=0.5105$ for the interaction between stage and iron conditions). Thus, D31 promoter activity remains constant over time in insects and the fluorescence of the $\mathrm{P}_{\mathrm{D} 31}-g f p[\mathrm{AAV}]$ fusion construct can be used as an in vivo reference standard.

Thereafter, gene expression was monitored by GFP quantification in infected larvae at each stage of the infectious process after normalization with the fluorescence from the constitutive D31 construct (Fig. 5B). We designed a statistical model in which relative promoter activity at a given infectious stage was compared with that of the previous stage, to determine whether gene expres- sion levels changed over time (see Experimental procedures). To report the iron availability in infected larvae treated or not with iron, we quantified expression of the siderophore enzyme encoding gene $x h b F$. In larvae without iron supplementation, the activity of the $x h b F$ gene promoter remained high and constant in living or recently deceased animals (stages ES, LS and EC) (Fig. 5B, solid line). Thus, the insect haemolymph fluid, like blood plasma, is an iron-starvation condition for bacterial growth. Furthermore, iron supplementation strongly decreased the level of $x h b F$ gene expression at these stages of infection (Fig. 5B, dashed line), indicating that addition of an exogenous source of iron modulates the iron availability in insects.

Quantification assays using the $\mathrm{P}_{\text {flic }}-g f p[\mathrm{AAV}]$ and $\mathrm{P}_{x a x A B}-g f p[\mathrm{AAV}]$ constructs first confirmed the late expression of both genes in infected larvae without iron supplementation (Fig. 5B, solid line). Indeed, хах $A B$ gene expression was negligible early in the infection but progressively increased between the LS and EC stages of infection $(t=1.759, P$-value $=0.0803)$ and between the EC and LC stages $(t=2.854, P$-value $=0.0048)$, peaking in insect cadavers 2 days after infection. The expression of the flic gene also gradually upregulated during infection and reached maximal expression in insect cadavers (Fig. 5B). In larvae with iron supplementation, fluorescence emitted by the $P_{x a x A B}-g f p[A A V]$ construct was strongly increased during the ES and LS stages of insect infection (5.1- and 3.6-fold respectively) (Fig. 5B, compare solid and dashed lines). Iron also upregulated the global expression of fliC at the ES stage (twofold, Fig. 5B) without changing the frequency of fluorescent bacteria (30 $\pm 7 \%$ without iron and $28 \pm 6 \%$ in presence of iron). Thus, artificial increases in the free iron content of infected insects shift the timing of FliAZdependent gene expression, such that the expression of fliC and xaxAB genes is induced before the death of the larvae. During infection without iron supplementation, we also noted that expression of the $x h b F$ gene decreased slightly but significantly $(t=1.708, \quad P$-value $=0.0893)$ between the EC and LC stages (twofold decrease), suggesting that free iron was released after the death of infected insects. Such iron availability may explain the increase of fliC and $x a x A B$ gene expression in dead larvae. Taken together, these findings indicate that the expression of the FliAZ-dependent genes during insect infection is significantly modulated by the availability of iron in infected insects.

\section{FliAZ-dependent genes are not expressed during the symbiotic stage of the $\mathrm{X}$. nematophila life cycle}

In natural conditions, $X$. nematophila is transported into insects by IJ nematodes (Martens et al., 2003). To 
A

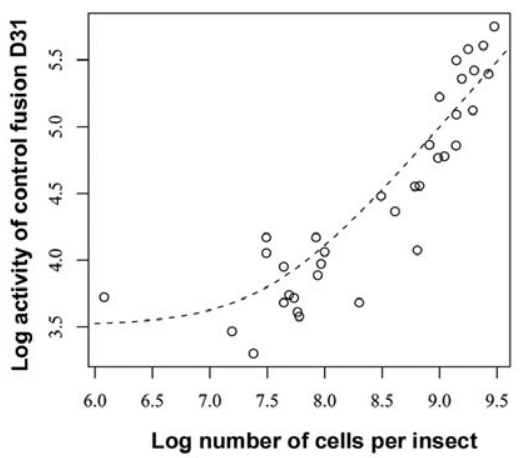

B

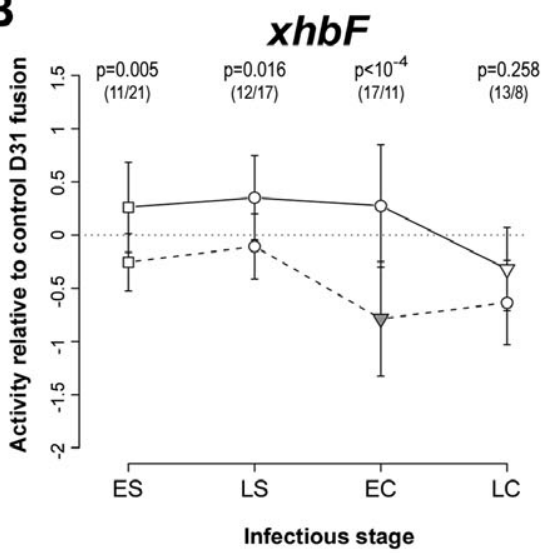

$x a x A B$

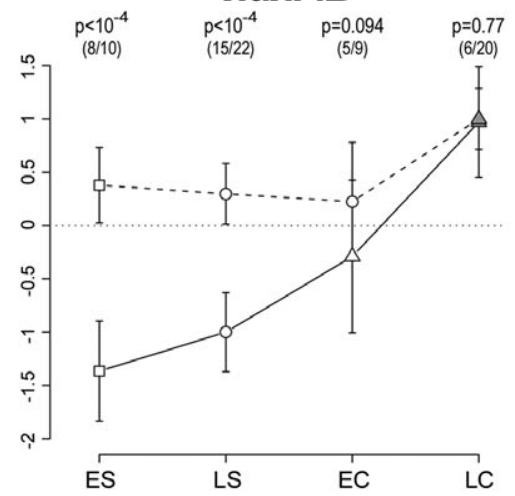

\section{flic}

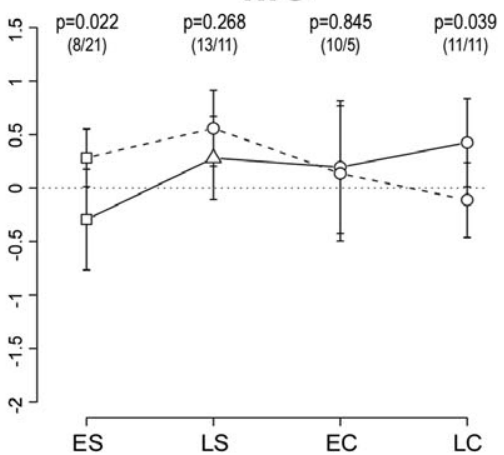

Fig. 5. Expression of the flagellin and haemolysin genes is temporally regulated during insect infection, as a function of iron availability. For each experiment, at time zero, we injected $10^{4}$ bacteria into the haemocoel of the insect larvae.

A. Relationship between the fluorescence obtained with the $\mathrm{P}_{\mathrm{D} 31}-g f p[\mathrm{AAV}]$ construct and the number of bacteria in insects. The dashed curve corresponds to a generalized linear model, with a gamma-distributed error and an identity link function.

B. FliAZ-dependent gene expression is modulated by free iron availability in infected insects. Each figure represents the log-transformed ratio of the fluorescence activity of the xaxAB, fliC or $x h b F$ constructs to that of the control D31 construct in larvae with and without iron supplementation (dashed lines and solid lines respectively). A value of zero thus indicates that the construct had a similar level of expression to the control D31 construct (dotted lines). Vertical bars are two times the standard error of the estimate. The triangles pointing upward indicate that the expression of the construct has increased since the previous stage; downward-pointing triangles indicate that the expression has decreased since the previous stage. The level of significance is indicated by whether the symbol is grey or white (grey: $P$-value is below 0.01 ; white, $P$-value is below 0.1 ). Open circles indicate no change in the expression of the gene since the previous stage (i.e. $P$-value $>0.1)$. The first stage, for which this test cannot be performed, is represented by open squares. The $P$-values indicated at the top of each graph correspond to a comparison between the relative activities obtained in insect larvae with and without iron supplementation. The numbers below the $P$-values are the sample size in this test, the first number indicating the number of measurements without iron supplementation, and the second number indicating the number of measurements with iron supplementation.

determine whether activation of the FliAZ regulon was restricted to the insect cadaver stage, $S$. littoralis larvae were infested with $S$. carpocapsae IJs associated with F1 strains carrying the various $g f p[A A V]$ constructs (see Experimental procedures for bacterium-nematode recombination). IJs were collected after their emergence from insect cadavers 9 days after infestation. Epifluorescence microscopy studies revealed that more than $70 \%$ of the IJs recently emerging from insects infected with the $\mathrm{F} 1\left(\mathrm{P}_{\mathrm{D} 31}-g f p[\mathrm{AAV}]\right)$ strain had fluorescent bacteria in their vesicles (Fig. 6). In contrast, no fluorescence was detected from bacteria within IJs emerging after association with $\mathrm{F} 1$ strains carrying $\mathrm{P}_{\text {flic }}-g f p[\mathrm{AAV}], \mathrm{P}_{x a x A B}$ $g f p[A A V], \mathrm{P}_{x h l B A}-g f p[\mathrm{AAV}]$ or $\mathrm{P}_{x h b F}-g f p[\mathrm{AAV}]$ constructs (Fig. 6). We then monitored $g f p[A A V]$ fusion construct expression over time in S. littoralis larvae infested with IJs associated with GFP-tagged bacteria. As in the injection assays, flagellin and haemolysin gene expression was first detected by epifluorescence microscopy at the time of insect death, whereas expression of the constitutive reporter $\mathrm{P}_{\mathrm{D} 31}-g f p[\mathrm{AAV}]$ or $\mathrm{P}_{x h b F}-g f p[\mathrm{AAV}]$ was recorded as early as the ES stage (data not shown). Thus, the expression of fliC, $x h I B A$ and $x a x A B$ occurred specifically at the time of death of the insect, regardless of the route of infection (direct injection or nematode infestation). These findings demonstrate that the flagellar regulon is not expressed in the nematode vesicle, suggesting that iron is not limited in this specialized compartment. 


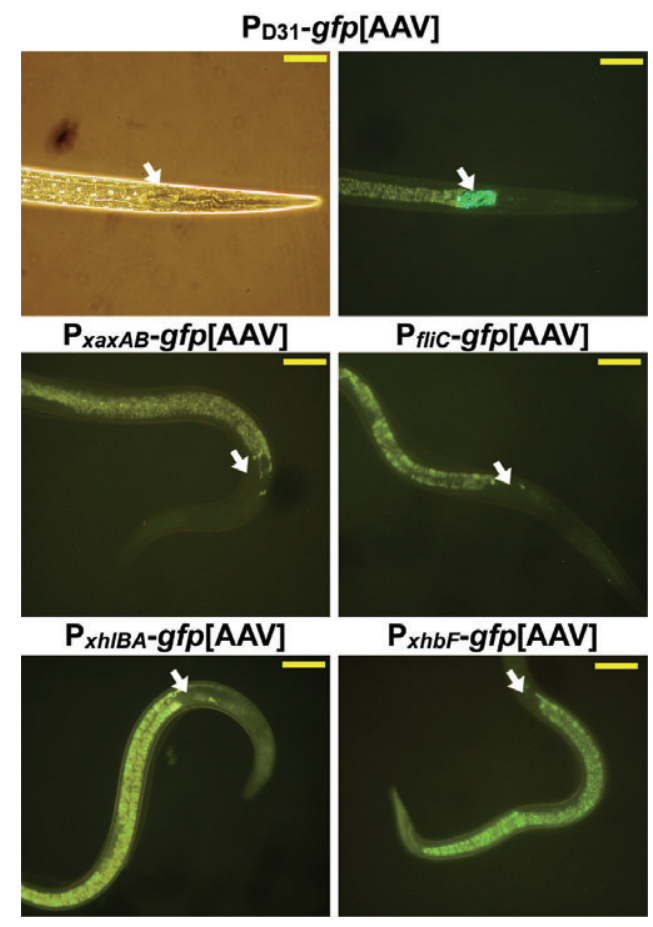

Fig. 6. The flagellin and haemolysin genes are not expressed in $X$. nematophila bacteria associated with IJ nematodes. Axenic nematodes of $S$. carpocapsae were associated with $F 1$ strains carrying $\mathrm{P}_{\mathrm{D} 31}-g f p[\mathrm{AAV}], \mathrm{P}_{\text {ffic }}-g f p[\mathrm{AAV}], \mathrm{P}_{\mathrm{xhlBA}}-g f p[\mathrm{AAV}]$,

$\mathrm{P}_{\text {xaxAB }}-g f p[\mathrm{AAV}]$ or $\mathrm{P}_{x b b F}-g f p[\mathrm{AAV}]$ constructs. Larvae of $S$. littoralis were infested with the various bacterium-nematode complexes and IJs were observed by fluorescence microscopy shortly after their emergence from insect cadavers. Nematode-carrying bacteria harbouring the $\mathrm{P}_{\mathrm{D} 31}-g f p[\mathrm{AAV}]$ construct were also photographed in phase contrast (upper left picture). Arrows indicate the bacterium-containing vesicle of the IJs. Bars represent $30 \mu \mathrm{m}$.

\section{Discussion}

FliA-dependent flagellin expression and FliZ-dependent haemolysin expression are restricted to the insect cadaver phase

The $X$. nematophila life cycle has been divided into three phases: insect infection, bacterial and nematode reproduction in the insect cadaver, and nematode transmission of $X$. nematophila to insect hosts (Richards and Goodrich-Blair, 2009). Gene inactivation studies have identified regulatory proteins that alter virulence in insects and affect expression of the flagellar regulon (Givaudan and Lanois, 2000; Goodrich-Blair and Clarke, 2007; Richards et al., 2008; Herbert et al., 2009). Among flagellar genes, the fliAZ operon has been identified as the key locus mediating the expression of genes involved in motility, lipase, protease and haemolysin activities (Park and Forst, 2006) and full virulence in insects (Lanois et al., 2008). Xenorhabdus must be able to control the expression of this gene network, to enable it to cope with the shifts in host environment inherent to the successful colonization of two invertebrate hosts. In this study, we observed that, regardless of the route of infection (bacterial injection or infestation by nematobacterial complexes), expression of the FliA-dependent flagellin gene fliC and the FliZ-dependent haemolysin genes $x а x A B$ and $x h / B A$ was high in dead insects whereas it remained negligible in living insects until the advanced stages of septicaemia. We also found that these fliAZ-dependent genes were not expressed in IJ nematodes. Activation of the flagellar cascade in dead insects may allow bacteria to move through cadaver towards nutrient-rich niches by chemotaxis, facilitating their rapid growth. Other activities encoded by the flagellar regulon (e.g. lipases, proteases and haemolysins) are also thought to contribute to the degradation of insect tissues, releasing nutrients for use by the nematodes. Consistent with this hypothesis, nematodes colonized with the $X$. nematophila $x / p A$ mutant display delayed IJ emergence and produce significantly fewer IJ progeny in total than nematodes colonized with wild-type strain, suggesting that the FliA-dependent lipase XIpA is involved in degrading insect lipids, thereby supporting nematode production (Richards and Goodrich-Blair, 2010). As $X$. nematophila must assemble the flagellar secretion system before it can secrete XIpA lipase (Park and Forst, 2006) and initiate motility, hydrolytic enzyme secretion may coincide with the dispersal of bacteria within insect cadavers.

Iron availability controls flagellar cascade expression in X. nematophila

An in vitro screening of conditions modulating the expression of FliAZ-dependent genes revealed that iron limitation drastically inhibits expression of both fliC and xax $A B$ genes. Iron signal may act on the flagellar cascade through the class I fIhDC operon because expression of the flhDC operon and the FlhDC-dependent class II flagellar gene $f l g B$ were repressed in presence of the ironchelator 2,2'-dipyridyl, by factors of 2 and 10 respectively (data not shown). The flagellar cascade and iron regulation have both been studied in detail in bacteria, but iron has rarely been reported to modulate bacterial motility (McCarter and Silverman, 1989; Guzzo et al., 1991; Deziel et al., 2003). By contrast to few data for motility, the stimulatory effect of iron starvation conditions on the production of haemolysins and toxins has been widely described in bacterial pathogens (for a review, see Litwin and Calderwood, 1993). Conversely, we show here an original iron regulation of haemolysin genes since both FliZ-dependent haemolysin genes, $x a x A B$ and $x h / B A$, are repressed in iron-limiting conditions in $X$. nematophila. $A$ previous study reported that the $x h / B A$ operon in $X$. nematophila was expressed three times more strongly in iron 
starvation conditions (Cowles and Goodrich-Blair, 2005). The discrepancy between the results of these two studies may be accounted for (i) by the use in Cowles' study of a different $X$. nematophila strain and (ii) by the determination of $x h / A$ mRNA levels in exponentially growing cells, in which $x h / B A$ expression levels are very low, being no more than $1 / 10$ that in the stationary phase of growth. To our knowledge, Xax and XhIA from $X$. nematophila are the first haemolysins to be described for which expression is inhibited by iron limitation. Although contrasting with the typical iron starvation-induced haemolysins involved in bacterial pathogen virulence, the downregulation of $x a x A B$ and $x h I B A$ gene expression in $X$. nematophila in the absence of iron is not surprising if we consider that these two haemolysins may have a role during the insect cadaver phase as recently demonstrated for another FliAZ-dependent genes (Richards and Goodrich-Blair, 2010).

Iron may constitute a signal for the transition between the insect infection and nematode reproduction phases

Organisms, including insects, have evolved mechanisms for stabilizing the iron availability through the control of its uptake, transport and storage (Locke and Nichol, 1992). Insect pathogenic bacteria have therefore developed a number of diverse mechanisms for scavenging iron from the host. Indeed, a recent study showed that the mutation of exbD in the entomopathogenic bacteria Photorhabdus, a gene encoding a component of the TonB system involved in iron uptake, leads to slower growth in insects, demonstrating a requirement for iron uptake for full virulence (Watson et al., 2005). Similarly, we found that expression of the siderophore-related gene $x h b F$ was strongly upregulated upon the infection of larvae by $X$. nematophila, indicating that iron uptake systems are triggered during Xenorhabdus-insect interactions. In addition to fulfilling metabolic requirements, iron also regulates the expression of the FliAZ regulon during insect infection. Indeed, artificial increases in the free iron content of infected insects shift the timing of fliC and $x a x A B$ expression, such that these genes are highly expressed in living larvae. Combined with inhibition of $x h b F$ expression in iron-treated larvae, these results indicate that iron sensing by Xenorhabdus is required to establish the sequential expression of siderophore and flagellar genes during insect infection. In the absence of iron supplementation, the increase of $x a x A B$ gene expression was partially correlated to the slight increase in iron availability. Most of the iron in insects is either linked to serum transferrins and ferritins circulating in the haemolymph or stored in cells, including enterocytes in the midgut in particular (Nichol et al., 2002). Interestingly, iron-rich sites are the first areas within the insect haemo- coel to be colonized by $X$. nematophila (Sicard et al., 2004). The expression dynamics of FliAZ-dependent genes may be related to sequential iron release during the final stages of insect infection. Large amounts of bacterial enzymes, such as proteases, may be produced just before the death of the insect, and their action begins to release free iron, through the proteolysis of extracellular iron-transport proteins. A second wave of iron release may then take place after cell lysis and midgut degradation, leading to the maximal levels of FliAZ-dependent gene expression observed during the insect cadaver stage. Iron may also result from the lysis of a part of the bacterial population in insects.

In conclusion, the flagellin gene fliC, and haemolysin genes хах $A B$ and $x h / B A$, controlled by the FliA and FliZ regulators, respectively, are specifically expressed at the time of the death of the infected insect and may be required for bacterial dissemination and tissue degradation in the cadaver, facilitating efficient nematode reproduction. Iron availability may constitute a signal for the upregulation of flagellin and haemolysin gene expression during the transition between the insect infection and nematode reproduction stages. This signalling pathway is part of a complex regulatory network tightly controlling the expression of specific sets of genes required for transitions between the symbiotic and pathogenic lifestyles of X. nematophila.

\section{Experimental procedures}

\section{Bacterial strains, plasmids and growth conditions}

The strains and plasmids used in this study are listed in Table S1. Bacteria were grown routinely in Luria-Bertani (LB) medium or Mot broth ( $1 \%$ tryptone, $0.5 \% \mathrm{NaCl}, 10 \mathrm{mM}$ $\left.\mathrm{MgSO}_{4}\right)$ at $28^{\circ} \mathrm{C}\left(X\right.$. nematophila) or $37^{\circ} \mathrm{C}$ (E. coll). Kanamycin $\left(20 \mathrm{mg} \mathrm{l}^{-1}\right)$, chloramphenicol $\left(15 \mathrm{mg} \mathrm{l}^{-1}\right)$, tetracycline $\left(7.5 \mathrm{mg} \mathrm{l}^{-1}\right), 2,2^{\prime}$-dipyridyl $(0.15 \mathrm{mM}), 4,4^{\prime}$-dipyridyl $(0.15 \mathrm{mM})$ and $\mathrm{FeSO}_{4}(0.3 \mathrm{mM})$ were added to the medium as required.

\section{Molecular genetic techniques and RNA preparation}

DNA manipulations were carried out as previously described (Ausubel et al., 1993). Plasmids were introduced into E. coli by transformation and transferred to $X$. nematophila by conjugative mating (Givaudan and Lanois, 2000). All constructs were sequenced by Millegen (Labège, France). The primers used in this study (Eurogentec) are described in Table S2. Total RNA was extracted with TRIzol reagent, according to the manufacturer's instructions (Invitrogen), and purified with the High Pure RNA Isolation kit (Roche), including incubation with DNase I. RNA concentration was determined by measuring absorbance at $260 \mathrm{~nm}$. For every RNA preparation, we assessed DNA contamination by carrying out a control PCR before qRT-PCR analysis. 
Construction of plasmids expressing gfp $[A A V]$ under the control of the fliC, xaxAB, xhIBA or xhbF gene promoters or a constitutive promoter (D31)

We obtained plasmids expressing the reporter gene gfp[AAV] under the control of gene promoters, by amplifying DNA fragments ( 200-450 bp) located upstream from flic, xaxA, $x h l B$ and $x h b F$ by PCR from F1 genomic DNA, with primers containing a Kpnl or BamHI restriction site. The PCR products were digested and inserted into the corresponding sites of pPROBE-gfp[AAV] or pPROBE'-gfp[AAV] vectors, yielding $\mathrm{P}_{\text {fiic }}-g f p[\mathrm{AAV}], \mathrm{P}_{\text {xaxAB }}-g f p[\mathrm{AAV}], \mathrm{P}_{\text {xhliBA}}-g f p[\mathrm{AAV}]$ and $\mathrm{P}_{\text {xhbF }}-$ gfp[AAV]. We constructed a plasmid for the constitutive expression of $g f p$, using the D3 promoter region previously identified in the screening of a $X$. nematophila promoter library, which we inserted into pBBR1-KGFP upstream from gfp mut3 (Sicard et al., 2004). For this study, we inserted the $1.1 \mathrm{~kb}$ Hindlll blunt end-Xbal fragment containing the D3 promoter region from the D3 plasmid between the Sall blunt end and Xbal sites of pPROBE-gfp[AAV] to yield $\mathrm{P}_{\mathrm{D} 31}-g f p[\mathrm{AAV}]$.

\section{Analysis of the expression of the gfp [AAV] constructs in vitro}

We studied the kinetics of gene expression in vitro, by inoculating $180 \mu \mathrm{l}$ of LB supplemented with kanamycin in blacksided, clear-bottomed 96-well plates (Greiner) with $20 \mu \mathrm{l}$ of a $1 / 50$ dilution of an overnight culture of the $\mathrm{F} 1$ strain carrying the various GFP constructs. The high total dilution factor $(1 / 500)$ ensured that GFP proteins from the pre-culture were diluted to below the threshold of detection before cell divisions and did not interfere with the monitoring of gene expression. Plates were then incubated for $40 \mathrm{~h}$ at $28^{\circ} \mathrm{C}$, with orbital shaking, in an Infinite M200 microplate reader (Tecan). Absorbance at $600 \mathrm{~nm}$ and GFP fluorescence intensity, with excitation at $485 \pm 4.5 \mathrm{~nm}$ and emission at $520 \pm 10 \mathrm{~nm}$, were measured every $30 \mathrm{~min}$. Specific fluorescence was obtained by dividing fluorescence units by the absorbance value. We analysed the effects of various chemical compounds on $x a x A B$ and fliC expression. Experiments were carried out as described above, except that LB was supplemented with 4,4'-dipyridyl, $\mathrm{FeSO}_{4}$, or the products listed in Fig. 2.

\section{Insect infection assays and GFP fluorescence recordings}

The common cutworm, S. littoralis, was reared on an artificial diet, at $23^{\circ} \mathrm{C}$, with a photoperiod of $12 \mathrm{~h}$. Fifth-instar larvae were selected.

Infection of insect larvae with the X. nematophila gfp[AAV] constructs. Experiments were performed as previously described (Sicard et al., 2004). Briefly, the surface of the insect larva was sterilized with $70 \%(\mathrm{v} / \mathrm{v})$ ethanol before the injection of bacteria into the haemocoel. We then used a Hamilton syringe to inject groups of 20 larvae with $20 \mu \mathrm{l}$ each of the appropriate dilution of bacterial cultures grown for $20 \mathrm{~h}$. Six independent experiments were performed for each strain. Treated larvae were incubated individually for up to $48 \mathrm{~h}$ and the time at which the insect died was recorded. A mean of $99.3 \%$ of bacteria retained the pPROBE plasmids $48 \mathrm{~h}$ after injection into insect larvae. We evaluated bacterial growth during insect infection, by counting bacteria within the insect body at various time points after injection. We removed the cuticles from five insect larvae per time point and crushed the soft larval bodies in a homogenizer (Ultra-Turrax TM). A low-speed centrifugation $(2000 \mathrm{~g})$ was performed to remove large pieces of tissue and the supernatants were collected. Samples were serially diluted and bacteria were counted under the microscope, using a Thoma-type counting chamber, at each stage of the infection process.

Quantification of bacterial gene expression in S. littoralis. We evaluated promoter activity in the infective bacterial population, by recording the fluorescence of soft larval body extracts (described above) on an Infinite M200 microplate reader (Tecan). We analysed 5-20 larvae from at least two independent experiments per fusion and per infection stage. Fluorescence values were subtracted from the autofluorescence values obtained for insects (at the same infection stage) infected with bacteria harbouring the promoterless pPROBE$g f p[A A V]$ vector. The resulting values were normalized with respect to the fluorescence values obtained for the $\mathrm{P}_{\mathrm{D} 31}-$ $g f p[\mathrm{AAV}]$ constitutive reporter fusion construct used as a reference (see Statistical analysis). For experiments involving iron supplementation, we simultaneously injected bacteria and $0.4 \mathrm{mg}$ of $\mathrm{FeSO}_{4}$ into the insect haemolymph. The monitoring of larval survival after iron supplementation revealed no effect on insect health.

Real-time imaging of larval fluorescence during infection. We monitored the spatial patterns of gene expression in whole infected insect larvae, with a fluorescence macroscope (Olympus $^{\mathrm{TM} M}$ MVX10 MacroView). Fluorescence imaging was performed with a 6 megapixel digital camera (CP6-CS, M42optic), including ultra-fast, full-resolution live image preview transformation software (MicrosCap-3, Spectrum software). Insect larvae were also dissected and fluorescent bacteria were localized as previously described (Sicard et al., 2003).

\section{Statistical analysis}

We first analysed expression of the control fusion $\mathrm{P}_{\mathrm{D} 31}-$ $g f p[A A V]$ construct during the four stages of infection. If promoter activity is constant during the infectious process, as expected, then fluorescence values should increase over time, in proportion to the number of bacterial cells counted in the insect larvae. We therefore used R statistical software to generate a generalized linear model (GLM) predicting the fluorescence of the control construct as a linear function of the estimated number of bacterial cells in the larvae. We assumed that the fluorescence data followed a gamma distribution and we used the identity link function. We then tested the hypothesis that fluorescence variation resulted solely from variations in the number of bacterial cells, by inspecting the residuals of this model. In particular, we checked for potential autocorrelation in the residuals that 
might result from non-linearity, using a Durbin-Watson test for autocorrelation.

For the detection of up- or downregulation of expression of the $x h b F$, fliC and $x a x A B$ constructs with respect to the control D31 construct, we generated a GLM fitting all fluorescence data, again assuming that fluorescence followed a gamma distribution, this time using a log link function. We first adjusted the GLM to predict the average log-transformed fluorescence of a gene $x, \log \left(F_{t+1}^{x}\right)$, for each stage of the infectious process, as $\log \left(F_{t+1}^{c}\right)$, the log-transformed fluorescence of the control fusion, plus a constant quantity $\delta_{t+1}^{x}$ : $\log \left(F_{t+1}^{x}\right)=\log \left(F_{t+1}^{c}\right)+\delta_{t+1}^{x}+\varepsilon, \quad \varepsilon$ being a gamma-distributed error term. The adjusted variable $\delta_{t+1}^{x}$ thus quantifies the difference in expression between a gene and the control construct. We used the same sort of statistical modelling to check for effects of iron supplementation on the level of expression of each construct. For the detection of up- or downregulation between infection stages for a given construct, we fitted a GLM with the same overall structure as that described above, but in which fluorescence value of a gene at a particular stage was predicted from that of the control D31 construct and from the fluorescence value of the gene at the previous stage: $\log \left(F_{t+1}^{x}\right)=\log \left(F_{t+1}^{\mathrm{c}} \frac{F_{t}^{\mathrm{c}}}{F_{t}^{x}}\right)+\lambda_{t+1}^{x}+\varepsilon$. In this model, we first predicted the fluorescence for a given gene if the expression of that gene had not changed since the previous stage. This prediction was obtained by multiplying the fluorescence of the control construct at stage $t+1$ by the ratio of the fluorescence of the gene to that of the control construct at stage $t$. We then added a quantity $\lambda_{t+1}^{x}$ to this first prediction. The adjusted variable $\lambda_{t+1}^{x}$ thus quantifies the change in expression of gene $x$ between stages $t$ and $t+1$.

\section{Insect infestation with S. carpocapsae containing} gfp $[A A V]$-expressing $X$. nematophila

Axenic nematodes of $S$. carpocapsae (SK27, France) were reared, as previously described (Sicard et al., 2004), from an in vitro $S$. carpocapsae production system, after egg sterilization. Living axenic offspring (IJs) were maintained in the laboratory by passage through larval-stage Galleria mellonella (wax moth) and harvested on White traps (White, 1927). We produced GFP-labelled bacterium-nematode complexes, using an in vivo technique (Sicard et al., 2003) in which the insect larvae were infected with bacterial constructs and axenic IJ nematodes. About 700 axenic IJs were first placed on a piece of filter paper in a Petri dish and incubated with 10 larvae of $S$. littoralis at room temperature. After $24 \mathrm{~h}$ of infestation, insect larvae were injected with $20 \mu \mathrm{l}$ ( 2000 bacteria) of bacteria harbouring gfp[AAV] constructs that had been grown for $20 \mathrm{~h}$. After the insects had died $(48 \mathrm{~h}$ post infestation), cadavers were transferred to White traps. Fourteen days after infestation, the IJs emerging from the cadavers were collected in Ringer's solution. These GFPlabelled bacterium-nematode complexes were then used to infest new S. littoralis larvae. Emergence (i.e. IJ production) was observed 9 days after infestation, for each bacterial construct. We used a Leica DMR microscope to visualize fluorescent bacteria in the vesicles of freshly emerged IJs. We checked the stability of bacterial plasmids after the second generation of IJs, by streaking appropriate dilutions of
IJ extracts onto selective plates (Sicard et al., 2004). For each GFP-labelled strain, more than $93 \%$ of the bacteria recovered from crushed IJs were found to be kanamycinresistant, indicating that the GFP-encoding plasmids persisted in the bacterial symbionts 9 days after infestation.

\section{qRT-PCR analysis}

Quantitative RT-PCR was performed in two steps. First, cDNAs were synthesized from $1 \mu \mathrm{g}$ of total RNA from Xenorhabdus F1 cultured in Mot broth alone or Mot broth supplemented with 2,2'-dipyridyl or with $2,2^{\prime}$ dipyridyl $+\mathrm{FeSO}_{4}$, using the Super Script II Reverse Transcriptase from Invitrogen and random hexamers (100 $\mathrm{ng}^{\mathrm{l}^{-1}}$ ) from Roche Diagnostics. qPCR was performed in triplicate with the LightCycler 480 SYBR Green I Master kit from ROCHE Diagnostics, with $1 \mu \mathrm{l}$ of CDNA synthesis mixture and $1 \mu \mathrm{M}$ of specific gene primers for $x a x A, x h l A, f l i C, x h b F$, sodB and exbB. The enzyme was activated by heating for $10 \mathrm{~min}$ at $95^{\circ} \mathrm{C}$. Reactions were performed in triplicate, using 45 cycles of $95^{\circ} \mathrm{C}$ for $5 \mathrm{~s}, 60^{\circ} \mathrm{C}$ for $5 \mathrm{~s}$ and $72^{\circ} \mathrm{C}$ for $10 \mathrm{~s}$, and were monitored with the Light Cycler 480 system (Roche). Melting curves were analysed for each reaction and each curve contained a single peak. Amounts of PCR products were calculated from standard curves obtained for PCR with serially diluted genomic DNA from $X$. nematophila F1. All data are presented as a ratio, with $m r e B$ used as the control gene (95\% confidence limits).

\section{ChIP assay}

The Fur-HA protein was generated by using the KpnLfur-HA (harbouring the ribosome binding site region of fliC and the first 12 codons of the fur sequence) and BamRfur-HA (designed to insert the HA sequence immediately upstream from the stop codon of the fur gene) primers to amplify a fur-HA PCR fragment from F1 genomic DNA. This PCR fragment was then inserted into pBBR1-MCS2 digested with Kpnl and BamHI. The resulting plasmid, pBB-Fur-HA, was transferred into the $X$. nematophila F1 strain and ChIP assays were performed, as previously described (Lanois et al., 2008). Briefly, the $X$. nematophila strain producing Fur-HA was cultured (to an $\mathrm{OD}_{540}$ of 1.2) in Mot broth or Mot broth supplemented with 2,2'-dipyridyl or with 2,2'dipyridyl $+\mathrm{FeSO}_{4}$. We then incubated $10 \mathrm{ml}$ of cultures in the presence of $1 \%$ formaldehyde for $30 \mathrm{~min}$ at room temperature and stopped the reaction by adding $125 \mathrm{mM}$ glycine and incubating for a further $5 \mathrm{~min}$. Cells were collected by centrifugation, washed twice with cold phosphate-buffered saline and lysed, and the resulting cell extracts were sonicated to obtain DNA fragments with a mean size of $600 \mathrm{bp}$. For the immunoprecipitation of Fur-cross-linked DNA, we incubated $700 \mu \mathrm{l}$ of the extract with $7 \mu \mathrm{l}$ of rabbit anti-HA Tag (Sigma) at room temperature for 90 min. Samples were incubated with Protein G Sepharose 4 fast flow (Amersham) for $1 \mathrm{~h}$ at room temperature and then centrifuged; $50 \mu \mathrm{l}$ of supernatant was removed for the preparation of total DNA (input DNA). Beads were then washed in several buffers and the immunoprecipitated material was eluted with $100 \mu$ of elution buffer. After proteinase $\mathrm{K}$ treatment, cross-linking in immunoprecipitated 
and total DNA was reversed by incubation at $67^{\circ} \mathrm{C}$ for $8 \mathrm{~h}$. Immunoprecipitated and total DNA were then purified with the QIAquick PCR Purification kit (Qiagen). The enrichment of the immunoprecipitated material with specific DNA fragments was determined by qPCR on a LightCycler 480 system (Roche), using the LightCycler 480 SYBR Green I Master kit and promoter-specific primers for the $x h b F, x a x A, x h / B, f l i C$, flhD and fliA genes and internal primers for the mreB and 16S genes.

\section{Acknowledgements}

We thank Nadège Ginibre and Hélène Girard for technical assistance. We also thank the Montpellier RIO Imaging facility for the use of their fluorescence macroscope and Philippe Clair from Montpellier GenomiX facility for expert technical assistance with real-time PCR. G.J. was supported by a 'jeune docteur' grant from INRA and this work was supported by Grant No. 2009_1133_01 from INRA.

\section{References}

Andersen, J.B., Sternberg, C., Poulsen, L.K., Bjorn, S.P., Givskov, M., and Molin, S. (1998) New unstable variants of green fluorescent protein for studies of transient gene expression in bacteria. Appl Environ Microbiol 64: 22402246.

Ausubel, F.M., Brent, R., Kingston, R.E., Moore, D.D., Seidman, J.G., and Struhl, K. (1993) Current Protocols in Molecular Biology. New York, USA: John Wiley and Sons.

Brillard, J., Ribeiro, C., Boemare, N., Brehelin, M., and Givaudan, A. (2001) Two distinct hemolytic activities in Xenorhabdus nematophila are active against immunocompetent insect cells. Appl Environ Microbiol 67: 25152525.

Cowles, C.E., and Goodrich-Blair, H. (2008) The Xenorhabdus nematophila nilABC genes confer the ability of Xenorhabdus spp. to colonize Steinernema carpocapsae nematodes. J Bacteriol 190: 4121-4128.

Cowles, K.N., and Goodrich-Blair, H. (2005) Expression and activity of a Xenorhabdus nematophila haemolysin required for full virulence towards Manduca sexta insects. Cell Microbiol 7: 209-219.

Cowles, K.N., Cowles, C.E., Richards, G.R., Martens, E.C., and Goodrich-Blair, H. (2007) The global regulator Lrp contributes to mutualism, pathogenesis and phenotypic variation in the bacterium Xenorhabdus nematophila. Cell Microbio/ 9: 1311-1323.

Deziel, E., Lepine, F., Milot, S., and Villemur, R. (2003) rhlA is required for the production of a novel biosurfactant promoting swarming motility in Pseudomonas aeruginosa: 3-(3-hydroxyalkanoyloxy) alkanoic acids (HAAs), the precursors of rhamnolipids. Microbiology 149: 2005-2013.

Escolar, L., Perez-Martin, J., and de Lorenzo, V. (1999) Opening the iron box: transcriptional metalloregulation by the Fur protein. J Bacteriol 181: 6223-6229.

Forst, S., and Boylan, B. (2002) Characterization of the pleiotropic phenotype of an ompR strain of Xenorhabdus nematophila. Antonie Van Leeuwenhoek 81: 43-49.

Forst, S.A., and Tabatabai, N. (1997) Role of the histidine kinase, EnvZ, in the production of outer membrane proteins in the symbiotic-pathogenic bacterium Xenorhabdus nematophilus. Appl Environ Microbiol 63: 962-968.

Forst, S., Dowds, B., Boemare, N., and Stackebrandt, E. (1997) Xenorhabdus and Photorhabdus spp.: bugs that kill bugs. Annu Rev Microbiol 51: 47-72.

Givaudan, A., and Lanois, A. (2000) flhDC, the flagellar master operon of Xenorhabdus nematophilus: requirement for motility, lipolysis, extracellular hemolysis, and full virulence in insects. J Bacteriol 182: 107-115.

Goodrich-Blair, H., and Clarke, D.J. (2007) Mutualism and pathogenesis in Xenorhabdus and Photorhabdus: two roads to the same destination. Mol Microbiol 64: 260-268.

Guzzo, A., Diorio, C., and DuBow, M.S. (1991) Transcription of the Escherichia coli fliC gene is regulated by metal ions. Appl Environ Microbiol 57: 2255-2259.

Herbert, E.E., and Goodrich-Blair, H. (2007) Friend and foe: the two faces of Xenorhabdus nematophila. Nat Rev Microbiol 5: 634-646.

Herbert, E.E., Andersen, A.W., and Goodrich-Blair, H. (2009) CpxRA influences Xenorhabdus nematophila colonization initiation and outgrowth in Steinernema carpocapsae nematodes through regulation of the nil locus. Appl Environ Microbiol 75: 4007-4014.

Ji, D., and Kim, Y. (2004) An entomopathogenic bacterium, Xenorhabdus nematophila, inhibits the expression of an antibacterial peptide, cecropin, of the beet armyworm, Spodoptera exigua. J Insect Physiol 50: 489-496.

Lanois, A., Jubelin, G., and Givaudan, A. (2008) FliZ, a flagellar regulator, is at the crossroads between motility, haemolysin expression and virulence in the insect pathogenic bacterium Xenorhabdus. Mol Microbiol 68: 516-533.

Litwin, C.M., and Calderwood, S.B. (1993) Role of iron in regulation of virulence genes. Clin Microbiol Rev 6: 137149.

Liu, X., and Matsumura, P. (1994) The FlhD/FlhC complex, a transcriptional activator of the Escherichia coli flagellar class II operons. J Bacteriol 176: 7345-7351.

Locke, M., and Nichol, H. (1992) Iron economy in insects: transport, metabolism, and storage. Annu Rev Entomol 37: 195-215.

Lynch, D., O'Brien, J., Welch, T., Clarke, P., Cuiv, P.O., Crosa, J.H., and O'Connell, M. (2001) Genetic organization of the region encoding regulation, biosynthesis, and transport of rhizobactin 1021, a siderophore produced by Sinorhizobium meliloti. J Bacteriol 183: 2576-2585.

McCarter, L., and Silverman, M. (1989) Iron regulation of swarmer cell differentiation of Vibrio parahaemolyticus. J Bacteriol 171: 731-736.

Martens, E.C., Heungens, K., and Goodrich-Blair, H. (2003) Early colonization events in the mutualistic association between Steinernema carpocapsae nematodes and Xenorhabdus nematophila bacteria. J Bacteriol 185: 31473154.

Martinez, J.L., Herrero, M., and de Lorenzo, V. (1994) The organization of intercistronic regions of the aerobactin operon of pColV-K30 may account for the differential expression of the iucABCD iutA genes. $J$ Mol Biol 238: 288-293.

Miller, W.G., Leveau, J.H., and Lindow, S.E. (2000) Improved gfp and inaZ broad-host-range promoter-probe vectors. Mol Plant Microbe Interact 13: 1243-1250. 
Nichol, H., Law, J.H., and Winzerling, J.J. (2002) Iron metabolism in insects. Annu Rev Entomol 47: 535-559.

Park, D., and Forst, S. (2006) Co-regulation of motility, exoenzyme and antibiotic production by the EnvZ-OmpRFlhDC-FliA pathway in Xenorhabdus nematophila. Mol Microbiol 61: 1397-1412.

Park, Y., Herbert, E.E., Cowles, C.E., Cowles, K.N., Menard, M.L., Orchard, S.S., and Goodrich-Blair, H. (2007) Clonal variation in Xenorhabdus nematophila virulence and suppression of Manduca sexta immunity. Cell Microbiol 9: 645-656.

Poinar, G.O., and Thomas, G.M. (1966) Significance of Achromobacter nematophilus Poinar et Thomas (Achromobacteriaceae, Eubacteriales) in the development of the nematode DD 136. Parasitology 56: 385-390.

Richards, G.R., and Goodrich-Blair, H. (2009) Masters of conquest and pillage: Xenorhabdus nematophila global regulators control transitions from virulence to nutrient acquisition. Cell Microbiol 11: 1025-1033.

Richards, G.R., and Goodrich-Blair, H. (2010) Examination of Xenorhabdus nematophila lipases in pathogenic and mutualistic host interactions reveals a role for $x I p A$ in nematode progeny production. Appl Environ Microbiol 76: 221229.

Richards, G.R., Herbert, E.E., Park, Y., and Goodrich-Blair, $\mathrm{H}$. (2008) Xenorhabdus nematophila IrhA is necessary for motility, lipase activity, toxin expression, and virulence in Manduca sexta insects. J Bacteriol 190: 4870-4879.

Sicard, M., Le Brun, N., Pages, S., Godelle, B., Boemare, N., and Moulia, C. (2003) Effect of native Xenorhabdus on the fitness of their Steinernema hosts: contrasting types of interaction. Parasitol Res 91: 520-524.

Sicard, M., Brugirard-Ricaud, K., Pages, S., Lanois, A., Boemare, N.E., Brehelin, M., and Givaudan, A. (2004) Stages of infection during the tripartite interaction between Xenorhabdus nematophila, its nematode vector, and insect hosts. Appl Environ Microbiol 70: 6473-6480.

Soutourina, O.A., and Bertin, P.N. (2003) Regulation cascade of flagellar expression in Gram-negative bacteria. FEMS Microbiol Rev 27: 505-523.

Thomas, G.M., and Poinar, G.O. (1979) Xenorhabdus gen. nov., a genus of entomopathogenic and nematophilic bacteria of the family Enterobacteriaceae. Int J Syst Bacteriol 29: $352-360$.

Vigneux, F., Zumbihl, R., Jubelin, G., Ribeiro, C., Poncet, J., Baghdiguian, S., et al. (2007) The xaxAB genes encoding a new apoptotic toxin from the insect pathogen Xenorhabdus nematophila are present in plant and human pathogens. J Biol Chem 282: 9571-9580.
Watson, R.J., Joyce, S.A., Spencer, G.V., and Clarke, D.J. (2005) The exbD gene of Photorhabdus temperata is required for full virulence in insects and symbiosis with the nematode Heterorhabditis. Mol Microbiol 56: 763-773.

White, G.F. (1927) A method for obtaining infective nematode larvae from cultures. Science 66: 302-303.

\section{Supporting information}

Additional Supporting Information may be found in the online version of this article:

Fig. S1. Iron-dependent expression of several genes in $X$. nematophila. The F1 strain was cultured in rich media (open

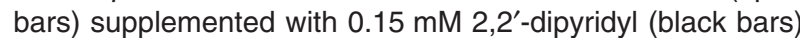

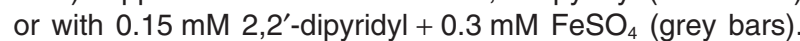
Total RNA from stationary-phase cultures $\left(\mathrm{OD}_{600}\right.$ of 1.4) was extracted and used for qRT-PCR analysis with specific internal primers for the $x h b F, x a x A, x h l A$ and fliC genes. Quantitative PCR was performed in triplicate and data are presented as a ratio, with $m r e B$ used as the control gene. Values are means of three independent assays and were compared using Student's $t$-test (95\% confidence limits). Significant differences with the standard rich media condition $(P$-value $<0.05)$ are indicated with asterisks $\left(^{*}\right)$.

Fig. S2. Iron-dependent expression of the flagellar regulon is not mediated by direct binding of the Fur regulatory protein. In vivo promoter binding to Fur was assayed by ChIP experiments. F1 expressing a Fur-HA construct was cultured in rich

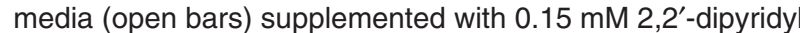

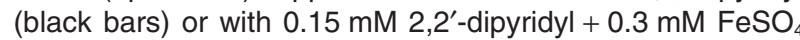
(grey bars). Promoter regions of the $x h b F, x a x A, x h / B$, fliC, $f / h D$ and fliA genes and the mreB internal region (non-target DNA) were quantified by $\mathrm{qPCR}$ in the total DNA and HA-immunoprecipitated DNA fractions from bacterial extracts $\left(\mathrm{OD}_{600}\right.$ of 1.2). Relative enrichment with the indicated promoter is expressed after normalization with respect to a control region in the $16 \mathrm{~S}$ gene. Values are means \pm the standard errors of three independent assays and were compared using unilateral Wilcoxon test. For each growth condition, significant enrichments $(P$-value $<0.01)$ of gene promoter region relative to $m r e B$ are indicated with asterisks $\left({ }^{*}\right)$

Table S1. Bacterial strain and plasmids used in this study. Table S2. Oligonucleotides used in this study.

Please note: Wiley-Blackwell are not responsible for the content or functionality of any supporting materials supplied by the authors. Any queries (other than missing material) should be directed to the corresponding author for the article. 